\title{
REVIEW
}

\section{The ADMIT series - Issues in Inhalation Therapy. 1) The goals of asthma treatment: can they be achieved?}

\section{*PN Richard Dekhuijzen ${ }^{a}$, Antoine Magnan ${ }^{b}$, Meinhard Kneussl', on behalf of the ADMIT Working Group ${ }^{d}$}

a Dept. of Pulmonary Diseases, Radboud University Nijmegen Medical Centre, The Netherlands

b EA 3287, Université de la Méditerranée, Hôpital Ste Marguerite, Marseille, France

c Wilhelminenspital, Vienna, Austria

${ }^{d}$ Members of the Aerosol Drug Management Improvement Team (ADMIT): Graham K Crompton, Edinburgh, UK, (Chair); Peter J Barnes, London, UK; Marielle Broeders, Nijmegen, The Netherlands; Chris Corrigan, London, UK; Lorenzo Corbetta, Università degli Studi di Firenze, Italy; PN Richard Dekhuijzen, Nijmegen, The Netherlands; Jean Christophe Dubus, Marseille, France; Meinhard Kneussl, Vienna, Austria; Federico Lavorini, Università degli Studi di Firenze, Italy; Mark L Levy, Edinburgh, UK; Antoine Magnan, Marseille, France; Joaquin Sanchis, Barcelona, Spain; Jose L Viejo, Hospital General Yagüe de Burgos, Spain; Walter Vincken, Brussels, Belgium; Thomas Voshaar, Moers, Germany; Thomas Hausen, Essen, Germany; Søren Pedersen, Kolding, Denmark; Antonio Ramalho de Almeida, Portugal

\section{Summary}

The widespread use of inhaled corticosteroids (ICS) since the early 1970's has meant that asthma is generally better controlled in comparison with previous decades. Nevertheless, recent patient interview surveys indicate that there is still a lot to gain in terms of abolishing daytime and nocturnal symptoms, and asthma exacerbations. It is important to use the terms asthma 'control' and asthma 'severity' in a correct way. Whereas asthma control reflects fluctuation in symptoms and lung function (or lack of them) over time, asthma severity reflects both asthma control and the need for medication. Thus, 'severity' is a property of the disease which reflects the degree of pathophysiological abnormality, whereas 'control' refers to the reduction of the clinical manifestations of disease achieved by treatment - thereby reflecting the adequacy of treatment. This introductory review, the first of a series of review papers to be published in this journal by the ADMIT team (see Appendix), discusses briefly our present knowledge of asthma control, its components, factors that may limit patients' ability to achieve optimal asthma control, and instruments to measure asthma control.

(C) 2007 General Practice Airways Group. All rights reserved.

PNR Dekhuijzen, et al. Prim Care Resp J 2007; 16(6): 341-348.

doi:10.3132/pcrj.2007.00081

Keyw ords Inhalation therapy, devices, asthma, control, treatment, severity

\section{Contents}

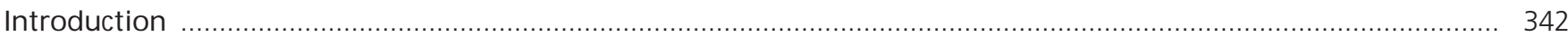

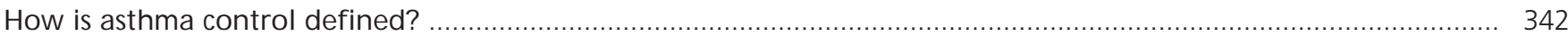

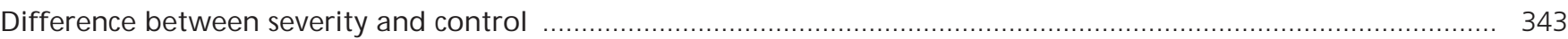

How can asthma control be measured? …

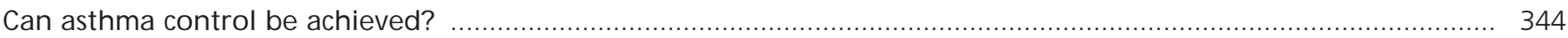

Which factors may limit asthma control and how can they be eliminated? ................................................ 344

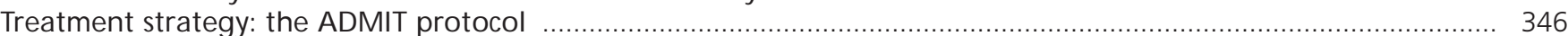

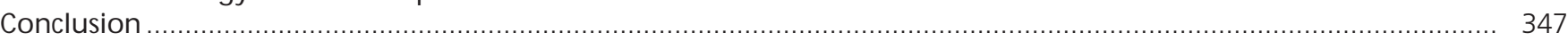

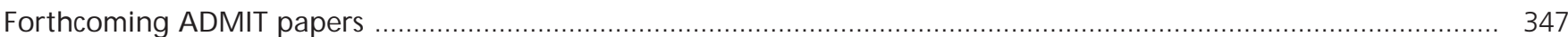

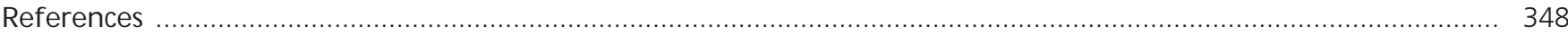

* Corresponding author: P.O. Box 9101, 6500 HB Nijmegen, The Netherlands.
Tel: +31-24-3614579 Fax: +31-24-3610324 E-mail: r.dekhuijzen@long.umcn.nl 


\section{Introduction}

The introduction of inhaled corticosteroids (ICS) in the early 1970's - and their subsequent widespread use - has meant that asthma is generally better controlled for most patients particularly in comparison with previous decades. ${ }^{1}$ Nevertheless, recent patient interview surveys indicate that there is still a lot to gain in terms of abolishing symptoms which can impede normal daily activities, normal leisure activities, and activities at school or work. Furthermore, nocturnal symptoms, recurrent symptoms, or asthma exacerbations, are present more frequently than sometimes assumed by the physician.

'Asthma control' is a frequently used but poorly defined term when assessing efficacy in international studies. ${ }^{2,3}$ In view of the fact that many patients treated with apparently efficacious therapy frequently complain of symptoms, it is pertinent to consider what other factors may have a role in the failure of individual patients to achieve full control of their symptoms. Consequently, one may question if asthma control is indeed achieved in these patients, and - if it isn't - what reasons there may be for patients not achieving optimal disease control.

This introductory review, the first of a series of review papers to be published in this journal by the ADMIT team (see Appendix), discusses briefly our present knowledge of asthma control, its components, and factors that may limit patients' ability to achieve optimal asthma control.

\section{How is asthma control defined?}

Optimal control of asthma should encompass lack of day- and night-time symptoms, no asthma exacerbations, no need for rescue medication, normal peak expiratory flow (PEF) rates, and no unwanted side effects from medication (see Table 1).4.6 Clearly this is the ideal, but not all patients with asthma can achieve these levels of disease control. Asthma severity subdivisions and levels of control have been described in the guidelines from the Global Initiative for Asthma (GINA) and the National Asthma Education and Prevention Program (NAEPP), ${ }^{6}$ each of which include consideration of each of the aforementioned items (see Tables 2 and 3). ${ }^{5-7}$ Subdivision of patients into those with 'total control' and 'well-controlled' asthma have been proposed and applied in recent studies (for example, the GOAL study ${ }^{8}$ ), and, although not validated in large scale epidemiological studies, this categorisation is appealing to the clinician and might appear to be a useful instrument.

European respiratory societies have provided guidelines for the achievement of asthma control. Interestingly, British ${ }^{9}$ and French $^{10}$ guidelines stipulate that asthma control can be qualified as being acceptable for a patient by taking into account not only symptoms, PEF and lung function, use of rescue medication and exacerbations (Table 4), but also the patient's aspirations and goals, the adverse effects of drugs and also the inconvenience of taking them. This view of asthma control - with a level of achievement varying from one patient to another - can be very useful in clinical practice; it allows a balance between the aims of the clinician (total control) and the aspirations and expectations of patients.

Asthma exacerbations are a manifestation of, and can help define, poor asthma control. However, there have been many different definitions of asthma exacerbations used in research studies over the years. ${ }^{2}$ Various criteria used to define exacerbations include: the presence of subjective day- and night-time symptoms such as dyspnoea, cough and wheeze; objective measures such as PEF or forced expiratory volume in one second $\left(\mathrm{FEV}_{1}\right)$ readings; healthcare utilisation measures such as the need for hospitalisation, accident and emergency $(A+E)$ or emergency room (ER) attendance, emergency general practitioner (GP) or practice nurse consultation; and acute treatment changes such as the prescribing of oral

\section{Table 1. Goals of asthma therapy according to GINA 5 and NAEPP6 guidelines.}

National Asthma Education and Prevention Program

(NAEPP) guidelines

Prevent chronic and troublesome symptoms

Maintain (near) "normal" pulmonary function

Maintain normal activity levels (including exercise and other

physical activities)

Prevent recurrent exacerbations of asthma and minimize the need

for emergency department visits and hospitalisation

Provide optimal pharmacotherapy with minimal or no adverse effects

Meet patients' and families' expectations of and satisfaction

with asthma care

Global Initiative for Asthma (GINA) guidelines

Achieve and maintain control of symptoms

Maintain pulmonary function as close to normal levels as possible

Maintain normal activity levels, including exercise

Prevent asthma exacerbations

Avoid adverse effects from asthma medications

Prevent development of irreversible airflow limitation

Prevent asthma mortality 


\begin{tabular}{|c|c|c|c|c|}
\hline Frequency of asthma symptoms & Intermittent & Mild persistent & Moderate persistent & Severe persistent \\
\hline Daytime & $<2$ times/week & $\geq 2$ times/week & Every day ( $\leq 2$ times/day) & 3 times daily \\
\hline Night time & 2 times/month & $\geq 2$ times/month & $\leq 2$ times/week & Most nights \\
\hline Severe episodes in past 12 months & $\leq 1$ time/week & $\geq 2$ times/week & Every day & Every day \\
\hline Exercise induced symptoms in past 12 months & $\leq 1$ time/week & ztimes/week & Every day & Every day \\
\hline Symptom frequency in typical week & $\leq 2$ times & 3-6 times & 7-20 times & 8-21 times \\
\hline
\end{tabular}

\begin{tabular}{|c|c|c|c|}
\hline Characteristic & $\begin{array}{l}\text { Controlled } \\
\text { (all of the following) }\end{array}$ & $\begin{array}{l}\text { Partly controlled } \\
\text { (Any measure present in any week) }\end{array}$ & Uncontrolled \\
\hline Daytime symptoms & None (twice or less/week) & More than twice/week & \multirow{4}{*}{$\begin{array}{l}\text { Three or more features } \\
\text { of partly controlled } \\
\text { asthma present in any } \\
\text { week }\end{array}$} \\
\hline Limitations of activities & None & Any & \\
\hline Need for reliever/rescue treatment & None (twice or less/week) & More than twice/week & \\
\hline Lung function (PEF or $\mathrm{FEV}_{1}$ ) & Normal & $\begin{array}{l}<80 \% \text { predicted or personal best } \\
\text { (if known) }\end{array}$ & \\
\hline
\end{tabular}

\section{Table 4. Criteria defining acceptable asthma control. ${ }^{10}$}

\begin{tabular}{ll} 
Criterion & Value or frequency \\
\hline Day-time symptoms & $<4$ days/week \\
Night-time symptoms & $<1$ night/week \\
Physical activity & Normal \\
Exacerbations & Mild, infrequent \\
Absence from work or school & None \\
Use of short-acting $\beta 2$-agonists & $<4$ doses/week \\
FEV $V_{1}$ or PEF & $>85 \%$ of personal best \\
PEF diurnal variation (optional) & $<15 \%$
\end{tabular}

steroids or use of nebulised bronchodilators. In their analysis of the 425 asthma exacerbations which occurred during the FACET study, ${ }^{11}$ Tattersfield et al ${ }^{12}$ defined severe exacerbations as the need for a course of oral corticosteroids or a reduction in morning PEF of $30 \%$ on two consecutive days. Exacerbations identified by the need for oral corticosteroids were associated with more symptoms and smaller changes in PEF than those identified on the basis of PEF criteria alone.

Finally, an ERS/ATS Joint Taskforce, under the chairmanship of Helen Reddel and Robin Taylor, is currently working on providing consensus recommendations on standard definitions and data collection methods for assessing asthma control, asthma severity and exacerbations in future clinical trials. ${ }^{2}$ Importantly, this report (which is about to be submitted for publication ${ }^{2 a}$ ) will permit better definition of asthma control and will help develop rational goals for asthma treatment.

\section{Difference between severity and control}

Some confusion may arise regarding the terms asthma 'control' and asthma 'severity'. Whereas asthma control reflects fluctuation in symptoms and lung function (or lack of them) over time, asthma severity reflects both asthma control and the need for medication. For example, one would not say that a patient is suffering from mild asthma if he/she is taking regular high dosages of inhaled corticosteroids and other add-on drugs such as long-acting beta-agonists (LABA), even if control of the disease is satisfactory. Recently, Bateman, ${ }^{13}$ and Stoloff and Boushey, ${ }^{14}$ have described 'severity' of a disease as a property of the disease which reflects the grade of pathophysiological abnormality, whereas 'control' refers to the reduction of the clinical manifestations of disease 


\section{Table 5. Asthma questionnaires to assess asthma control. ${ }^{4}$}

ACQ Includes 6 Questions and the $\mathrm{FEV}_{1}$. Five questions are those rated most important by a survey of 100 clinicians in 18 countries. The sixth question concerns rescue inhaler use

ACT Includes 5 questions that most closely correlate patients'symptoms with their specialists'evaluations of control

AQLQ Includes 32 questions in 4 domains (symptoms, activity limitations, environmental stimuli and emotional function) that measure the functional problems that are most troublesome to adults with asthma

ATAQ Assesses 4 measures of control over a 4-week period and scores 1 point for each-self-perceived control, missed activities, nighttime waking and use of rescue inhalers

AQ30 Includes 30 questions which determine everyday life health status estimates in patients with asthma. Questions answered "Yes" $=1$ and "No" or "N/A" = 0 ; a total score of $0=$ no asthma and $30=$ very severe asthma. Correlates with AQLQ and clinical variables

ABP Measures asthma distress by bother; patient's confidence of asthma knowledge, perception of the quality of care, and confidence in managing asthma attacks

$\mathrm{ACQ}=$ Asthma Control Questionnaire; $\mathrm{ACT}=$ Asthma Control Test; $\mathrm{AQLQ}=$ Asthma Quality of Life Questionnaire; ATAQ $=$ Asthma Therapy Assessment Questionnaire; $\mathrm{AQ30}=$ Asthma Questionnaire 30; $\mathrm{ABP}=$ Asthma Bother Profile.

achieved by treatment - thereby reflecting the adequacy of treatment.

\section{How can asthma control be measured?}

Asthma control comprises several domains which are partly interrelated. Day- and night-time symptoms can be recorded by patients using symptom diaries, PEF readings can be recorded by patients themselves, and PEF and FEV 1 readings can be measured in the consulting room. Data can be collected on healthcare utilisation measures - such as hospital attendance and emergency GP and nurse consultation - and on the prescribing of acute courses of oral steroids or nebulised bronchodilators.

Another set of measures includes surrogate markers of inflammation, such as hyperreactivity to methacholine or histamine, and markers in (induced) sputum such as the number of eosinophils and exhaled nitric oxide (NO) levels. At present, these markers are not included in routine clinical assessment of control, although measurement of exhaled NO levels is becoming more feasible. ${ }^{15}$

Several questionnaires have been developed to measure asthma control - see Table $5 .{ }^{4} \mathrm{~A}$ frequently used example is the Asthma Control Test (ACT) ${ }^{16}$ as shown in Table 6.

\section{Can asthma control be achieved?}

As shown in Table 1, the GINA guidelines specify eight goals for the long-term control of asthma: minimal chronic symptoms, minimal exacerbations, no emergency visits, minimum need for as-required beta-2-agonists, no limitations of daily activities, near-normal PEF, PEF circadian variation of less than $20 \%$, and minimal adverse effects from asthma medication.
However, several recent surveys have shown that asthma control is not achieved in a large number of patients. The Asthma Insights and Reality (AIR) surveys aimed to assess control of asthma and the current state of asthma management with respect to the GINA guidelines. The AIR surveys were the Asthma in America survey in the United States in 1998, the Asthma Insights and Reality in Europe (1999), followed by surveys in Asia-Pacific and Japan in 2000 and in Central and Eastern Europe in 2001. ${ }^{17}$ In all participating regions, asthmatic patients performed equally poorly against the various GINA goals, with a consistently high proportion of subjects reporting daytime, night-time, and exercise-induced symptoms. A remarkable finding across all regions was the discrepancy between the numbers of reported symptoms and patients' perception of their asthma control. The surveys indicate that $32-49 \%$ of patients experiencing severe symptoms, and $39-70 \%$ of patients with moderate symptoms, believed their current level of asthma control to be 'good or 'complete'. Rabe and coworkers ${ }^{17}$ noted that there was a tendency for patients to overestimate control and underestimate severity, suggesting a willingness to accept symptoms and lifestyle limitations as unavoidable consequences of their disease. This might, in part, be responsible for the poor outcomes seen elsewhere in these surveys because patients who consider their symptoms controlled are unlikely to seek further medical advice.

\section{Which factors may limit asthma control and how can they be eliminated?}

Many factors may contribute to inadequate asthma control. A number of issues are listed in Table 7. Assuming that asthma 


\section{Table 6. Asthma Control Test: Items and scores. ${ }^{16}$}

\section{Asthma Control Test ${ }^{\mathrm{TM}}$}

1. In the past 4 weeks, how much of the time did your asthma keep you from getting as much done at work, school or at home?

\begin{tabular}{|c|c|c|c|c|}
\hline All of the time & Most of the time & Some of the time & A little of the time & None of the time \\
\hline 0 & 0 & 0 & 0 & 0 \\
\hline 1 & 2 & 3 & 4 & 5
\end{tabular}

2. During the past 4 weeks, how often have you had shortness of breath?

\begin{tabular}{|c|c|c|c|c|}
\hline More than once a day & Once a day & 3 tot 6 times a week & Once or twice a week & Not at all \\
\hline 0 & 0 & 0 & 0 & 0 \\
\hline 1 & 2 & 3 & 4 & 5
\end{tabular}

3. During the past 4 weeks, how often did your asthma symptoms (wheezing, coughing, shortness of breath, chest tightness or pain) wake you up at night or earlier than usual in the morning?

\begin{tabular}{|c|c|c|c|c|}
\hline $\begin{array}{c}4 \text { or more nights } \\
\text { a week }\end{array}$ & 2 to 3 nights a week & Once a week & Once or twice & Not at all \\
\hline 0 & 0 & 0 & 0 & 0 \\
\hline 1 & 2 & 3 & 4 & 5
\end{tabular}

4. During the past 4 weeks, how often have you used your rescue inhaler or nebulizer medication (such as albuterol)?

\begin{tabular}{|c|c|c|c|c|}
\hline $\begin{array}{c}3 \text { or more times } \\
\text { per day }\end{array}$ & $\begin{array}{c}\text { 1 or 2 times } \\
\text { per day }\end{array}$ & $\begin{array}{c}\text { 2 or 3 times } \\
\text { per week }\end{array}$ & Once a week or less & Not at all \\
\hline 0 & 0 & 0 & 0 & 0 \\
\hline 1 & 2 & 3 & 4 & 5 \\
\hline
\end{tabular}

5. How would you rate your asthma control during the past 4 weeks?

\begin{tabular}{|c|c|c|c|c|}
\hline Not controlled at all & Poorly controlled & Somewhat controlled & Well controlled & Completely controlled \\
\hline 0 & 0 & 0 & 0 & 0 \\
\hline 1 & 2 & 3 & 4 & 5
\end{tabular}

Asthma control test ${ }^{\mathrm{TM}}$ (c) 2002 by QualityMetric Incorporated. All Rights Reserved.

Asthma control test ${ }^{\mathrm{TM}}$ is a trademark of QualityMetric Incorporated

is the correct (and only) diagnosis, the underlying severity of the disease may prevent achievement of optimal control in some patients. Even in the well-conducted GOAL (Gaining Optimal Asthma controL) study only $40 \%$ of all patients reached predefined levels of optimal asthma control and only $60-70 \%$ reached the level of 'well-controlled' asthma. ${ }^{8}$ It is important to remember that a significant proportion reached these degrees of control only with high dosages of ICS (fluticasone) which are associated with local side effects and systemic effects such as cortisol suppression. ${ }^{18}$ This demonstrates the difficulties in getting the balance right in terms of attaining the goals of asthma treatment by achieving asthma control but at the same time limiting the potential for ICS side effects.

The physician should consider whether all bronchial triggers have been identified, including exposure to unknown 
Table 7. Issues to consider if asthma is not under control.

\begin{tabular}{lll} 
A Is it really Asthma? & $\begin{array}{l}\text { Consider other diagnoses, } \\
\text { e.g. hyperventilation, vocal cord } \\
\text { dysfunction, Churg-Strauss } \\
\text { syndrome, carcinoid }\end{array}$ \\
\hline B $\quad$ Are all Bronchial & $\begin{array}{l}\text { Exposure to unknown triggers at } \\
\text { triggers known? }\end{array}$ & $\begin{array}{l}\text { work, hobby, rhino-sinusitis, } \\
\text { gastro-oesophageal reflux (GORD), } \\
\text { intolerance to medications }\end{array}$ \\
\hline C $\quad$ Is Compliance optimal & $\begin{array}{l}\text { Does the patient use the } \\
\text { medication at the prescribed } \\
\text { dosages? }\end{array}$ \\
\hline D $\quad$ Can the patient handle & $\begin{array}{l}\text { Is the patient able to use the } \\
\text { device correctly? }\end{array}$ \\
\hline E $\quad$ Is Every small airway & $\begin{array}{l}\text { Does the anti-inflammatory } \\
\text { medication reach the peripheral } \\
\text { reached? }\end{array}$ & compartment of the lung?
\end{tabular}

triggers at work or when doing other activities such as hobbies, rhino-sinusitis, gastro-oesophageal reflux (GORD), and intolerance to medications. It is important to check whether or not the patient is able to use the inhaler device correctly, and in some patients with nocturnal awakenings and/or severe asthma it may be of clinical importance to ensure that the anti-inflammatory medication reaches the peripheral compartment of the lung.
Compliance with, and adherence to, treatment schedules should be checked and re-checked. The subject of patient compliance with asthma treatment is complex. Issues include the need for discussion between the patient and healthcare professionals concerning the patient's health beliefs and the various explanatory models that can be used, conceptualisation of asthma as a short term acute intermittent illness rather than the medical model of a persisting inflammatory process, and the goals and willingness of patients to trade off inconvenience against benefit. ${ }^{19-22}$ These issues will be addressed in more detail in forthcoming ADMIT papers.

\section{Treatment strategy: the ADMIT protocol}

Recently, the ADMIT Group has proposed a practical algorithm in order to improve the instructions given to the patient regarding optimal use of their inhaler. ${ }^{23}$ Figure 1, an asthma therapy adjustment flow chart, shows the way in which the healthcare professional can monitor and check the patient's use of inhaled medication and make treatment changes according to various criteria. At each consultation, the physician or nurse should check that the patient has few symptoms, is leading a normal life, performs regular exercise, is on low-dose relief medication, and is not taking any additional medication. If all these conditions are met then therapy should be stepped down according to treatment guidelines, and another appointment should be scheduled for a symptom check. If, however, the patient answers 'no' to any of the checklist questions then compliance and aggravating

Figure 1. Achieving asthma control: Recommendation for therapy adjustment. Modified from the original published in Respiratory Medicine ${ }^{23}$ with permission from Elsevier

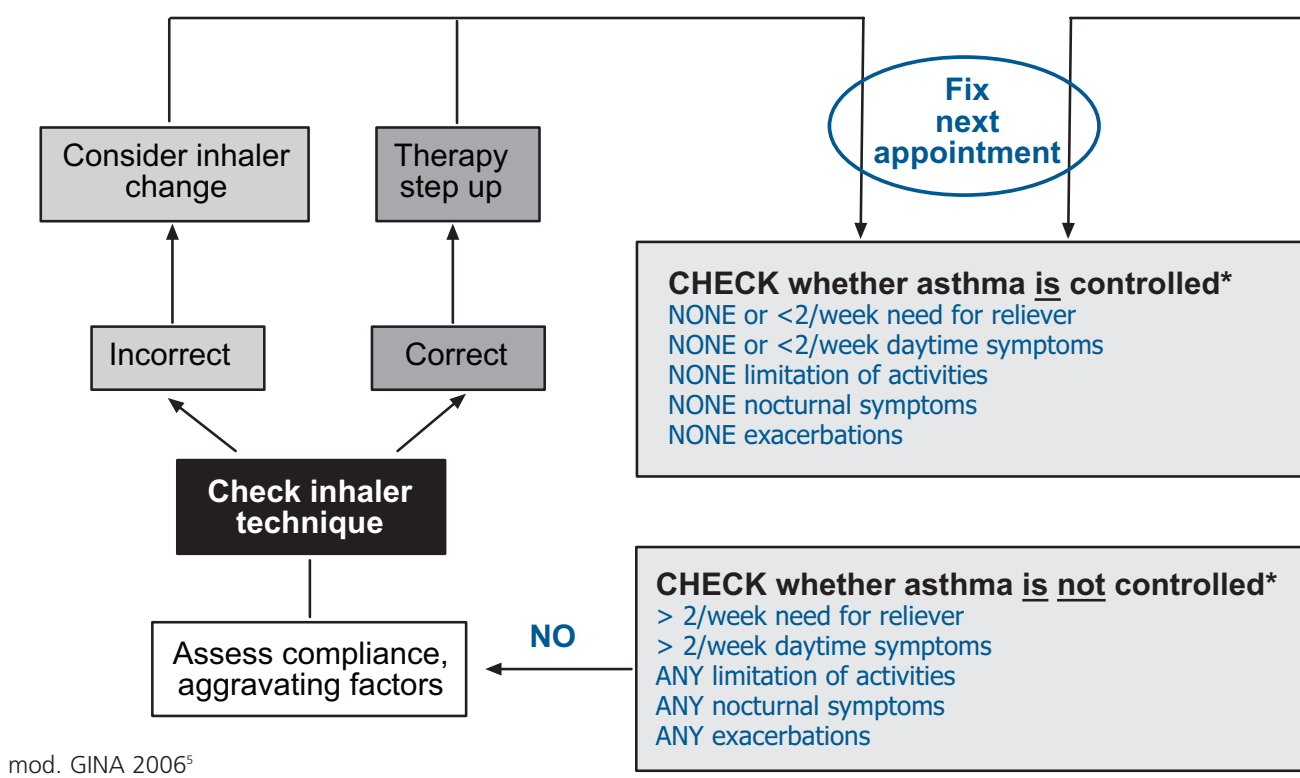


factors should be assessed. Most importantly, inhalation technique should be assessed. If inhalation technique is incorrect and cannot be corrected adequately, a change in inhaler device should be considered. If, on the other hand, inhalation technique is correct then asthma therapy should be stepped up according to treatment guidelines and another appointment scheduled in order to check symptoms. ${ }^{23}$

\section{Conclusion}

Using several scoring systems, it appears that large numbers of patients do not achieve acceptable levels of asthma control. There is a wide range of explanations for this, including inaccurate diagnosis, failure to identify triggers, poor compliance, and incorrect use of inhaled medication. The latter can easily be improved by following strict algorithms to direct optimal choice and usage of an inhalation device.

\section{Forthcoming ADMIT papers}

A forthcoming series of papers on Issues in Inhalation Therapy will appear in this Journal over the next year. The series will focus on inhalation treatment in adults and children with obstructive airways diseases. Future themes include: the aims of therapy in patients with asthma and COPD; the characteristics of inhaled medication including side effects and their use in daily practice in stable and unstable disease; compliance issues; ways to optimise inhaler use; inhalation issues in children; inhalation devices in COPD; reasons to choose a specific device first; and the actions to be taken prior to altering an inhaled drug or its dosage.

\section{Conflict of interest declaration - the ADM IT Working Group}

The Aerosol Drug Management Improvement Team (ADMIT) is a consortium of European respiratory physicians with a common interest in promoting excellent delivery of inhaled drugs for asthma and COPD. It is supported by an unrestricted educational grant from MEDA AB. Members of ADMIT receive a small honorarium for attending meetings from MEDA $A B$ and travel expenses are reimbursed.

\section{Appendix Members of the Aerosol Drug Management Improvement Team (ADMIT) - affiliations and individual conflict of interest declarations:}

Professor Graham K Crompton (Chair)

14 Midmar Drive, Edinburgh EH10 6BU, Edinburgh, UK

Has been reimbursed by Meda $A B$ for attending conferences and/or giving presentations, and he serves as a consultant to Meda $A B$.

Profesor Peter J Barnes

National Heart and Lung Institute, Imperial College London, UK

Has been reimbursed for attending conferences and/or giving talks by, and has acted as a consultant for, Altana/Nycomed, AstraZeneca, Boehringer Ingelheim, GlaxoSmithKline, Novartis, Pfizer, Meda AB.

Professor Marielle Broeders

University M edical Centre Nijmegen, The Netherlands

Acts as a consultant to Meda AB.

Professor Chris Corrigan

Department of Asthma, Allergy and Respiratory Science, Guy's, Kings's and St.
Thomas' School of Medicine, London, UK

Has been reimbursed for attending conferences and/or giving talks by ScheringPlough, Allergy Therapeutics, Med AB, UCB Pharma. His department has received research grants from GlaxoSmithKline, Novartis, ALK-Abello, Allergy Therapeutics. He has acted as a consultant for Meda AB, GlaxoSmithKline, MSD, Allergopharma, Joachim Ganzer AB.

Professor Lorenzo Corbetta

Università degli Studi di Firenze, Unità Funzionale di M edicina Respiratoria, Italy Has been reimbursed for attending conferences and/or giving talks by Meda $A B$, Boehringer Ingelheim, GlaxoSmithKline, Menarini. He acts as a consultant for Meda AB. His department receives unrestricted educational grants from Altana/Nycomed, AstraZeneca, Boehringer Ingelheim, GlaxoSmithKline, Novartis, Pfizer, Meda AB, Chiesi.

Professor PN Richard Dekhuijzen

Radboud University Nijmegen Medical Centre, The Netherlands

Has been reimbursed for attending conferences and/or giving talks by GlaxoSmithKline, AstraZeneca, Boehringer Ingelheim and Zambon. He serves as a consultant to GlaxoSmithKline, AstraZeneca, Merck, Meda AB, Altana Pharma, Boehringer Ingelheim and Pfizer. His department receives unrestricted research and educational grants from AstraZeneca, GlaxoSmithKline, Boehringer Ingelheim, Pfizer, Actelion, Altana and Teva and receives research grants and/or fees per patient from Novartis and Boehringer Ingelheim for performing trials.

Professor Jean Christophe Dubus

Unité de Medicine Infantile, Marseille, France

Has been reimbursed for attending conferences and/or giving talks by GlaxoSmithKline, Ivax and AstraZeneca. He has acted as a consultant for Novartis and Meda AB. His department has received research grants from Roche, Aerogen and Pari.

Professor Meinhard Kneussl

Wilhelminenspital, Vienna, Austria

Has been reimbursed for attending conferences and/or giving talks by Actelion, AOP, Pfizer, AstraZeneca, GlaxoSmithKline and Boehringer Ingelheim. He also serves as a consultant to Actelion, AOP, Pfizer, Boehringer Ingelheim and Meda AB.

Professor Federico Lavorini

Università degli Studi di Firenze Unità Funzionale di Medicina Respiratoria, Italy Has been reimbursed for attending conferences and/or giving talks by Menarini Industrie Farmaceutiche, AstraZeneca and Pfizer. He serves as a consultant to Meda AB.

Dr Mark L Levy

Clinical Research Fellow, Division of Community Health Sciences: GP Section, University of Edinburgh, UK

Has been reimbursed for attending conferences and/or giving talks by, and has acted as a consultant for, AstraZeneca, GlaxoSmithKline, Ivax, 3M, Novartis, MSD, Altana, Meda AB, Trinity Chiesi, Boehringer Ingelheim, Ranbaxy, Innovata Biomedica and Schering Plough. He has received research grants from Ivax, Boehringer Ingelheim, GlaxoSmithKline, Schering Plough and AstraZeneca.

$\mathrm{He}$ is the Editor-in-Chief of the Primary Care Respiratory Journal, but was not involved in the editorial review of, nor the decision to publish, this article.

Professor Antoine Magnan

Université de la M éditerranée, Hôpital Ste Marguerite, Marseille, France

Has been reimbursed for attending conferences and/or giving talks by MSD, Stallergenes, AstraZeneca, Novartis, Meda AB, Boehringer Ingelheim. His department has received research grants from UCB and Novartis. He has acted as a consultant for AstraZeneca, Novartis and Meda AB.

Professor Joaquin Sanchis

Departament de Pneumologia, Hospital de la Santa Creuide Sant Pau, Universitat Autónoma de Barcelona, Spain

Has been reimbursed for attending conferences and/or giving talks by AstraZeneca and Meda AB. His department has received research grants from Novartis and AstraZeneca. He has acted as a consultant for GlaxoSmithKlilne, AstraZeneca, Ferre and Meda $A B$.

Professor Jose L Viejo

Hospital General Yagüe de Burgos, Spain

Has been reimbursed for attending conferences and/or giving talks by 
GlaxoSmithKline, AstraZeneca, Boehringer Ingelheim, Pfizer, Zambon, MSD. He has acted as a consultant for GlaxoSmithKline, Zambon, Meda AB, Boehringer Ingelheim, Pfizer.

\section{Professor Walter Vincken}

Academisch Ziekenhuis VUB, Dienst Pneumologie, Brussels, Belgium

Acts as a consultant to Meda AB.

Professor Thomas Voshaar

Krankenhaus Bethanien, Moers, Germany

Has been reimbursed for attending conferences and/or giving talks by Boehringer Ingelheim, Pfizer, Asche Chiesi, UCB, Meda AB, Altana, GlaxoSmithKline, Novartis, MSD, TEVA and $3 \mathrm{M}$. He has acted as a consultant for Boehringer Ingelheim, Pfizer, Meda $A B$ and MSD.

Dr Thomas Hausen

General Practice, Grafenstrasse 52, Essen, Germany

Acts as a consultant to Meda AB.

Professor Søren Pedersen

Professor of Paediatric Respiratory Medicine, University of Southern Denmark, Paediatric Research Unit, Kolding Hospital, Denmark

Has been reimbursed for attending conferences and/or giving talks by Altana/Nycomed, GlaxoSmithKline, Meda AB. He has received research grants from Altana/Nycomed, AstraZeneca, GlaxoSmithKline. He has acted as a consultant to Altana/Nycomed, GlaxoSmithKline, Meda AB

Dr Antonio Ramalho de Almeida

Pr. General Humberto Delgado 267, Porto, Portugal

Acts as a consultant to Meda AB.

\section{References}

1. Crompton GK. A brief history of inhaled asthma therapy over the last fifty years. Prim Care Resp J 2006;15(6):326-31. doi:10.1016/j.pcrj.2006.09.002

2. Partridge MR. What do the words "asthma control" and "exacerbation" really mean? Prim Care Resp J 2004;13(4):179-80. doi:10.1016/j.pcrj.2004.09.001

2a Reddel H. Personal communication, 15th November 2007.

3. Juniper EF, Chauhan A, Neville E, Chatterjee A, Svensson K, Mork AC, Stahl E. Clinicians tend to overestimate improvements in asthma control: an unexpected observation. Prim Care Resp J 2004;13(4):181-4. doi:10.1016/ j.pcrj.2004.04.003

4. Hanania NA. Revisiting asthma control: How should it best be defined? Pulm Pharmacol Ther 2007;20(5):483-92.

5. Global Initiative for Asthma. Global Strategy for Asthma Management and Prevention. Bethesda, MD: National Heart, Lung and Blood Institute, National Institutes of Health; 2004. NIH publication 02-3659. Updated November 2006.

6. National Asthma Education and Prevention Program. Expert Panel Report 2: Guidelines for the Diagnosis and Management of Asthma . Bethesda, MD: National Heart, Lung and Blood Institute, National Institutes of Health; 1997, MIH publication 97-4051. Updated 2006.

7. Rees J. Asthma control in adults. BMJ 2006;332:767-71.

8. Bateman ED, Boushey HA, Bousquet J, Busse WW, Clark TJ, Pauwels RA, Pedersen SE; GOAL Investigators Group. Can guideline-defined asthma control be achieved? The Gaining Optimal Asthma ControL study. Am J Respir Crit Care Med 2004;170(8):836-44.

9. British Guideline on the Management of Asthma. Thorax 2003;58 suppl 1.

10. Nicolas Roche, Hugues Morel, Philippe Martel, Philippe Godard. Clinical practice guidelines: Medical follow-up of patients with asthma - Adults and adolescents. Respir Med 2005;99:793-815.

11. Pauwels RA, Lofdahl CG, Postma DS, Tattersfield AE, O'Byrne P, Barnes PJ, Ullman A. Effect of inhaled formoterol and budesonide on exacerbations of asthma. Formoterol and Corticosteroids Establishing Therapy (FACET) International Study Group. N Engl J Med 1997;337(20):1405-11.

12. Tattersfield AE, Postma DS, Barnes PJ, Svensson K, Bauer CA, O'Byrne PM, Loffdahl CG, Pauwels RA, Ullman A. Exacerbations of asthma: a descriptive study of 425 severe exacerbations. The FACET International Study Group. Am J Respir Crit Care Med 1999;160(2):594-9.

13. Bateman ED. Severity and control of severe asthma. J Allergy Clin Immunol 2006;117(3):519-21.

14. Stoloff SW, Boushey HA. Severity, control, and responsiveness in asthma. J Allergy Clin Immunol 2006;117:544-8.

15. Gruffydd-Jones K, Ward S, Stonham C, Macfarlane TV, Thomas M. The use of exhaled nitric oxide monitoring in primary care asthma clinics: a pilot study. Prim Care Resp J 2007;16(6):349-56. doi:10.3132/pcrj.2007.00076

16. Nathan RA, Sorkness CA, Kosinski M, Schatz M, Li JT, Marcus P, Murray JJ, Pendergraft TB. Development of the asthma control test: a survey for assessing asthma control. J Allergy Clin Immunol 2004;113:59-65.

17. Rabe KF, Adachi M, Lai CK, Soriano JB, Vermeire PA, Weiss KB, Weiss ST. Worldwide severity and control of asthma in children and adults: the global asthma insights and reality surveys. J Allergy Clin Immunol 2004;114:40-7.

18. Lipworth BJ. Systemic adverse effects of inhaled corticosteroid therapy: A systematic review and meta-analysis. Arch Intern Med 1999;159(9):941-55.

19. Lloyd A, Mclntosh E, Rabe KF, Williams A. Patient preferences for asthma therapy: a discrete choice experiment. Prim Care Resp J 2007;16(4):241-8. doi:10.3132/pcrj.2007.00052

20. Johansson G, Stallberg B, Tornling G, Andersson S, Karlsson GS, Falt K, Berggren F. Asthma treatment preference study: a conjoint analysis of preferred drug treatments. Chest 2004;125(3):916-23.

21. Haughney J, Barnes G, Partridge M, Cleland J. The Living \& Breathing Study: a study of patients' views of asthma and its treatment. Prim Care Resp J 2004;13(1):28-35. doi:10.1016/j.pcrj.2003.11.007

22. Partridge MR, Hill SR. Enhancing care for people with asthma: the role of communication, education, training and self-management. 1998 World Asthma Meeting Education and Delivery of Care Working Group. Eur Respir J 2000;16(2):333-48

23. Crompton GK, Barnes PJ, Broeders M, Corrigan C, Corbetta L, Dekhuijzen PNR, Dubus JC, Magnan A, Massone F, Sanchis J, Viejo JL, Voshaar T; Aerosol Drug Management Improvement Team. The need to improve inhalation technique in Europe: a report from the Aerosol Drug Management Improvement Team. Respir Med 2006;100:1479-94.

\section{Available online at http://w ww.thepcrj.org}

